\title{
The role of PEG conformation in mixed layers: from protein corona substrate to steric stabilization avoiding protein adsorption
}

\author{
Joan Comenge ${ }^{1}$, and Víctor F. Puntes ${ }^{1,2,3 *}$ \\ ${ }^{1}$ Insitut Català de Nanociència i Nanotecnologia, Campus UAB, 08193 Barcelona, Spain \\ ${ }^{2}$ Institut Català de Recerca i Estudis Avançats, 08010 Barcelona, Spain \\ ${ }^{3}$ Vall d Hebron Research Insitute, 08035 Barcelona, Spain \\ *Corresponding author's e-mail address: victor.puntes@icn.cat \\ Present address: Joan Comenge, Institute of Integrative Biology, University of Liverpool, L69 7ZB Liverpool, UK
}

Published online: 23 March 2015 (version 1)

Cite as: Comenge J and Puntes VF, ScienceOpen Research 2015 (DOI: 10.14293/S2199-1006.1.SOR-MATSCI.A0Z6OM.v1)

Reviewing status: Please note that this article is under continuous review. For the current reviewing status and the latest referee's comments please click here or scan the QR code at the end of this article.

Primary discipline: Nanotechnology

Keywords: gold nanoparticles, protein corona, mixed layers

\begin{abstract}
Although nanoparticles (NPs) have been traditionally modified with a single ligand layer, mixture of ligands might help to combine different functionalities and to further engineer the NP surface. A detailed study of the competition between an alkanethiol (11-mercaptoundecanoic acid) and SH-PEG for the surface of AuNPs and the resultant behaviors of this model nanoconjugate is presented here. As a result, the physicochemical properties of these conjugates can be progressively tuned by controlling the composition and especially the conformation of the mixed monolayer. This has implications in the physiological stability. The controlled changes on the SH-PEG conformation rather than its concentration induce a change in the stabilization mechanism from electrostatic repulsion to steric hindrance, which changes the biological fate of NPs. Importantly, the adsorption of proteins on the conjugates can be tailored by tuning the composition and conformation of the mixed layer.
\end{abstract}

\section{INTRODUCTION}

In recent years, synthesis and conjugation of nanoparticles (NPs) have experienced a rapid evolution making possible advanced medical applications such as carriers for drug delivery [1, 2], contrast agents for imaging [3], and radiosensitizers for radiotherapy [4] among others. However, this rapid evolution is often linked to an incomplete characterization or a lack of understanding on the mechanisms involved on the final application. Surprisingly, while the structureactivity relationship is a paradigm in biology, the molecular conformation of nanoconjugates is too often ignored with huge consequences [5]. In fact, the ability of engineering the physicochemical properties of these conjugates is important to tune biological responses such as cell uptake, protein adsorption or immunogenicity among others $[6,7]$. This is the case of stealthing with the FDA-approved polymer polyethylene glycol (PEG) [8-10]. After the simple, but widely exploited, use of PEG as surfactant for NPs (just by adding it in excess), many efforts are now being carried out unveiling the mechanism of action and to properly characterize these nanosystems to achieve a better control over physicochemical properties such as colloidal stability at working conditions or interactions with proteins [6,10-13]. This is of special interest in environments where high ionic strength solutions, such as the biological fluids (e.g. blood and cell culture media, CCM), induce a compression of the solvated double layer of NPs leading to their aggregation if a steric stabilizing agent is not present [14, 15]. Unfortunately, the loss of colloidal stability might lead to unpredicted biological responses [16]. Thus, it cannot be underestimated, especially when high concentration of NPs are required [17]. Proteins present in biological media often play the role of stabilizing agent by forming a protective protein corona on the surface of the NPs, thus avoiding their aggregation [18, 19]. Albuminization is therefore a wellknown strategy for biocompatibilization, but some biological responses such as NPs uptake by cells might depend on the presence or absence of a protein corona [7, 20, 21]. Although a deep understanding of the protein corona has been achieved in recent years [191 22], the control over its formation is still a "yes or no" process which depends mainly on the use of surfactants with different affinity toward proteins [23]. For example, large chain PEGs or zwitterionic polymers avoid protein adsorption, while alkanethiols do not prevent the formation of a protein corona. However, physicochemical properties conferred by alkanethiols self-assembled monolayers (SAMs) might be lost when using polymeric agents such as PEG. For example, the possibility of further chemistry on the monolayer might be limited by the lower number of functional groups that can be loaded onto the NP with PEG 
respect to the densely SAMs obtained with alkanethiols. It is therefore challenging to find complementary methodologies which allow a control of the protein adsorption and colloidal stability, retaining the chemical functionality conferred by alkanethiols SAMs [24].

In the present work, AuNPs were functionalized with different ratios of two surfactants widely used to functionalize and stabilize NPs: 11-Mercaptoundecanoic acid (MUA) and thiolated PEG (SH-PEG, $3.4 \mathrm{KDa}$ ). MUA is deprotonated at physiological pHs and it has been used many times for drug loading [25] and EDC coupling [26]. MUA provides electrostatic repulsion while SH-PEG provides steric hindrance (these are the two existing strategies to provide repulsion forces to avoid NP aggregation). The mixed layer has been studied in terms of composition and conformation and the combined synergistic behavior of both surfactants analyzed. Interestingly, it is shown here how the changes on the physicochemical properties of the conjugates are closely correlated to changes on the conformation of the SH-PEG molecules rather than on its concentration on the monolayer. This not only influences the stability of the conjugate under different conditions, but also the modulation of protein adsorption. Additionally, an improved stability is achieved without losing the chemical functionality given by the carboxylic groups of MUA. This study allows a better understanding on the most widely used mechanisms of AuNPs stabilization in biological media: pegylation and protein corona.

\section{RESULTS AND DISCUSSION Competing biconjugation of MUA and SH-PEG}

About $14.6 \pm 1.5 \mathrm{~nm}$ AuNPs were synthesized in sodium citrate following a seeding growth approach as described in the literature [27] (Figure 1). This approach is based on a kinetically controlled growth of sodium citrate AuNPs, avoiding new NP nucleation, NP coalescence and instability (pH drop) during the growth process. These AuNPs were later functionalized with mixtures of MUA and SH-PEG (MW 3.4 $\mathrm{KDa}$ ). MUA is an alkanethiol widely used in the study of SAMs due to the high affinity of the thiol for the gold, the presence of a hydrophobic chain and because it is depronated at physiological pHs, conferring electrostatic stability to the NPs [24]. PEG is a linear synthetic polymer build up by repeating [- $\left.\mathrm{CH}_{2} \mathrm{CH}_{2}-\mathrm{O}-\right]$ units. It is uncharged, water soluble, inert, considered as non-toxic, and approved for clinical use [28]. Pegylation of NPs has been proposed several times as a methodology to confer stability to quantum dots and AuNPs in biological media [29]. Additionally, it has been extensively

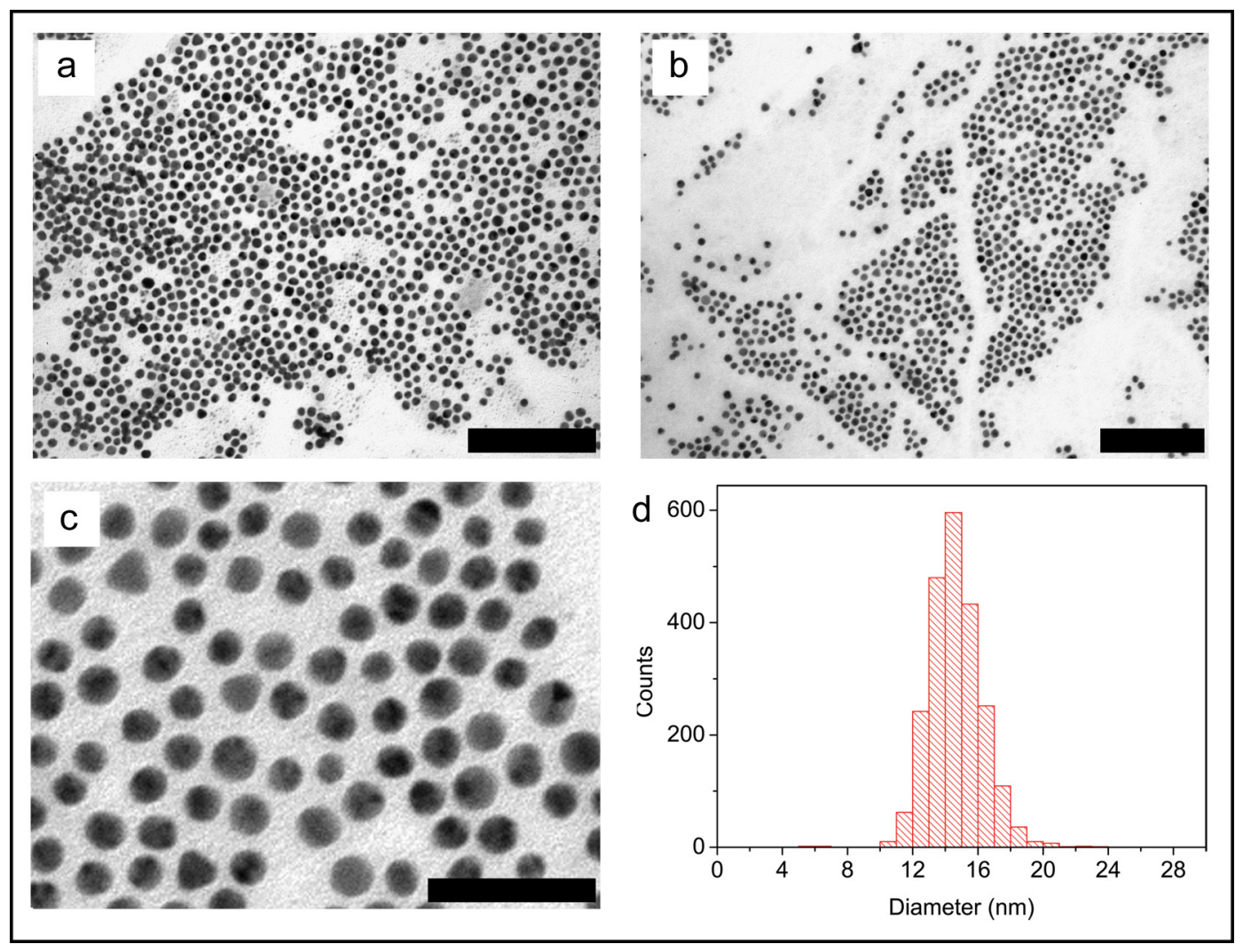

Figure 1. Representative TEM images of MUA-capped AuNPs and size distribution. $14.6 \pm 1.5 \mathrm{~nm}$ AuNPs were synthesized following a seeding growth mechanism. They were functionalized with MUA before imaging. Scale bars are $200 \mathrm{~nm}$ (A, B) and $40 \mathrm{~nm}$ (C). Size distribution is showed in the histogram (D). 
used to stealth polymeric nanostructures from being rapidly cleared by the immune system [8, 30-32], since it efficiently avoids opsonization (the process by which opsonins bind to the surface of foreign matter so that it will be readily identified and engulfed by phagocytes).

First, we analyzed how the addition of different ratios of SHPEG/MUA affects the loading of these molecules (Figure 2a). Since both molecules compete for the AuNP surface, it is important to assess whether the proportion of both components in solution is maintained or not on the AuNPs surface. It is surprising how in many reports the proportion in solution is assumed to be that on the NP, as if different molecules had identical affinity for the NP surface. The final concentration of the sum of both species was kept constant $(30 \mu \mathrm{M})$ and only the ratio of both components was modified. SH-PEG-FITC (MW $3.4 \mathrm{KDa}$ ) was used to quantify the amount of this molecule on the surface by measuring the absorbance of the supernatants after removing all AuNPs by centrifugation, or by measuring the fluorescence of the attached SH-PEG-FITC after digestion of AuNPs with sodium cyanide of the previously washed AuNPs [10]. In both cases, the loading of SH-PEG on the NPs followed a linear trend reaching a final concentration on the NPs of approximately $2.3 \mu \mathrm{M}$ (Figure 2). This value corresponds to a final coverage of 334 molecules per NP, representing a footprint of $2.0 \mathrm{~nm}^{2}$.

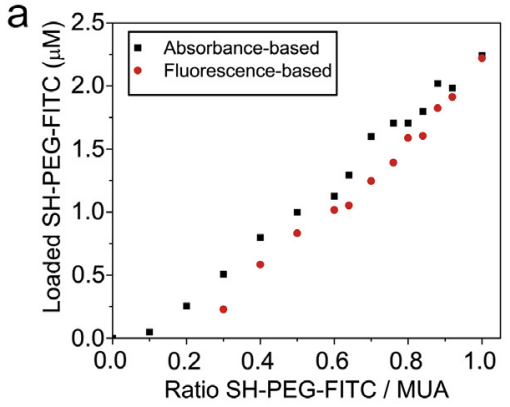

C

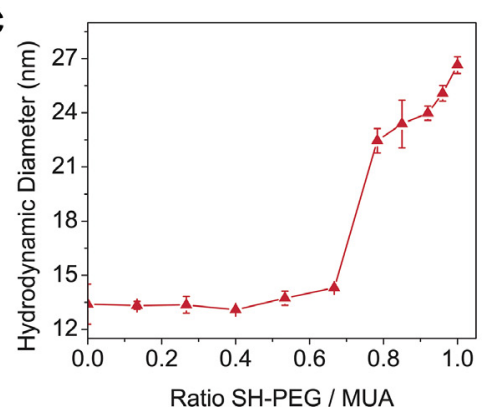

Note that in the case of lowest ratios (highest [MUA]), this could not be easily measured due to the difficulty to totally digest the NPs, likely due to the compactness of the layer when MUA is the highly predominant component of the SAM [33]. The quantification of MUA is not relevant for this study and it was not directly measured. However, one could roughly estimate the amount of MUA assuming that the surface which is not occupied by SH-PEG would be covered by MUA. For example, in the case of the ratio 0.5 , the amount of SH-PEG loaded is ca. $0.9 \mu \mathrm{M}$, which corresponds to 131 molecules per NPs and a $39 \%$ of surface coverage. Assuming that the remaining $61 \%$ is covered by MUA, and taking into account that the footprint for alkanethiols on gold is reported to be $0.21 \mathrm{~nm}^{2}$ [34], the number of MUA per NP would be ca. 1945, which is 15 times higher than the amount of SH-PEG. Therefore, even if both attach with a thiol group, the resulting interactions and packing between neighboring molecules favors MUA over the SH-PEG molecules. This can be explained by the fact that MUA is a smaller molecule than SH-PEG with a hydrophobic chain and a hydrophilic head that favors the formation of dense SAMs on AuNPs [24]. Also, while MUA is expected to be always radial to the surface [35], molecules as PEG, at low densities, are expected to be in a folded conformation in what is known as the mushroom
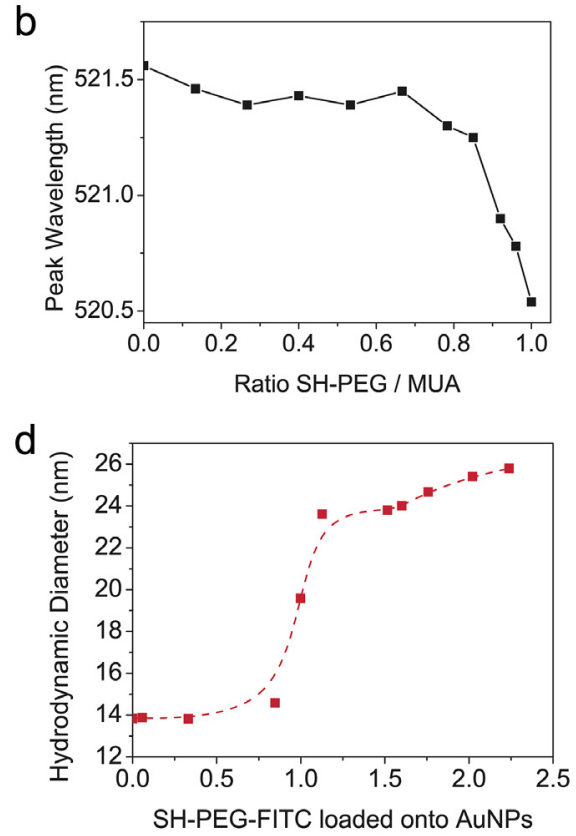

Figure 2. Mixed layer characterization. (a) Loading of SH-PEG-FITC on AuNPs in function of the ratio SH-PEG-FITC / MUA. In the absorbance-based method, the amount of SH-PEG-FITC on the supernatant was measured after NP removal and subtracted to the initial amount added to know the amount loaded on the NPs. In the fluorescence based method, the NPs were washed from the excess and digested with NaCN to ultimately measure the fluorescence of the SH-PEG bond to the NPs. (b) SPR peak in function of the SH-PEG / MUA shows a discontinuous behavior of the SPR shift. This different behavior is due to a change on the SH-PEG conformation. This is corroborated after DLS measures (c). (d) The great raise on the hydrodynamic diameter at loadings ca. $0.9 \mu \mathrm{M}$ is indicative of the point at which the stretching of SH-PEG chains is produced. 
conformation [36]. At higher densities, PEG molecules also take a radial conformation, known as brush conformation [36]. Note that the behavior observed in the loading of SH-PEG on the NP (Figure 2a) shows that the amount of SH-PEG loaded depends linearly on the amount added in solution. Interestingly, the surface plasmon resonance (SPR) showed a discontinuous behavior (Figure 2b): The SPR position was only slightly shifted from ratios SH-PEG / MUA $=0$ (all MUA) to ratios $\approx 0.7$ ([MUA $\left.]_{\text {added }} /[\mathrm{SH}-\mathrm{PEG}]_{\text {added }}\right)$. From this point, a shift to shorter wavelengths occurred. The SPR peak dropped sharply from 521.4 to $520.5 \mathrm{~nm}$. This discontinuous behavior is not due to a differential loading of both components in function of the ratio since the loading of SH-PEG increases constantly as the proportion of SH-PEG added increases. Therefore, this discontinuity is not related to great changes on the layer composition, but on conformational changes. It has been demonstrated that a stretching of a polymeric chain produce a blue shift of the SPR, due to the decrease of ligand density in the vicinity of the AuNP [37]. It is also known that a high density of SH-PEG grafted on the AuNPs surface lead to a change of conformation from mushroom to brush [36, 38, 39]. Thus, the observed blue shift is likely to be caused by a stretching of the SH-PEG chains, induced at high grafting densities of SH-PEG. To corroborate this point, the hydrodynamic diameter of the conjugates, measured by dynamic light scattering (DLS), was also monitored in function of the $\mathrm{SH}-$ PEG / MUA ratios (Figure 2c). DLS gives the measure of the diameter that a sphere with the same translational diffusion speed than the corresponding NP would have [40] and its value is influenced by the length of the ligands as well as by the compactness of the layer. Interestingly, a similar behavior than previously shown for UV-VIS was observed here: A slight increase of the hydrodynamic diameter was produced until ratios $\approx 0.7$ in which the hydrodynamic diameter raised rapidly from $14.9 \mathrm{~nm}$ to $27.6 \mathrm{~nm}$. This is in agreement with the predicted stretching of the SH-PEG chains. This is even more clearly observed when the hydrodynamic diameter is plotted in function of the SH-PEG loaded onto AuNPs (Figure 2d). The initial loading of SH-PEG did not cause a significant change on the hydrodynamic diameter. On the contrary, when the amount of SH-PEG loaded on the AuNPs reached values around $1 \mu \mathrm{M}$ (ratio $\approx 0.7$ ), the hydrodynamic diameter dramatically increased. Thus, the change on SH-PEG conformation is produced here at loadings around the $45 \%$ of the maximum amount of SH-PEG able to load onto the AuNPs $(2.3 \mu \mathrm{M})$. It is important to know when the conformational change of PEG takes place since this is what induces a strong change on the physicochemical behavior and colloidal stability as it will be demonstrated in the following sections.

\section{Stability in physiologic media. Dependence on the AuNPs concentration}

One of the goals of using mixed layer is to gain stability in physiological media. Thus, the limit of stability for one component (MUA) monolayers should be determined to work beyond this limit for mixed layer stability assessment. MUA-capped AuNPs were prepared and concentrated up to $2.4 \times 10^{14} \mathrm{NP} / \mathrm{mL}(0.39 \mu \mathrm{M})$ in order to assay their stability in physiologic conditions at significant doses. Note that an AuNP concentration in common synthesis is $0.5-10 \mathrm{nM}[27$, 41]. However, higher concentration of AuNPs is often required for in vivo and in vitro applications.

About $10 \% \mathrm{v} / \mathrm{v}$ of AuNPs solution at different concentrations was added to CCM (DMEM without phenol red supplemented with $10 \%$ fetal bovine serum, FBS) and the peak position of the SPR was measured by UV-VIS. Aggregation of AuNPs is known to broaden and shift to longer wavelengths the SPR band and to increase the scattering at the $600-800 \mathrm{~nm}$ range [42]. As expected, it was confirmed that colloidal stability depended on the AuNPs concentration (Figure 3). Low concentrations of AuNPs in CCM $\left(\leq 4.75 \times 10^{12} \mathrm{NP} / \mathrm{mL}\right)$ are very stable due to the formation of the widely described protein corona: Briefly, proteins are adsorbed on the NPs surface, in this case on the MUA layer, conferring stability against aggregation by steric repulsion $[19,43]$. The stabilizing role of the protein corona was confirmed since all NPs aggregated when they were incubated in DMEM not supplemented with FBS. On the other hand, highly concentrated AuNPs $\left(\geq 9.5 \times 10^{12} \mathrm{NP} / \mathrm{mL}\right)$ aggregated even in media supplemented with FBS, as showed by the red-shift and by the broadening of the SPR band. This indicates that proteins in media were not capable of stabilizing high concentrations of MUA-capped AuNPs. Protein in CCM is approximately at 0.1 $\mathrm{mM}$ while the highest concentration of AuNPs used here is 2.4 $\times 10^{13} \mathrm{NP} / \mathrm{mL}(39 \mathrm{nM})$. Since the amount of protein in the

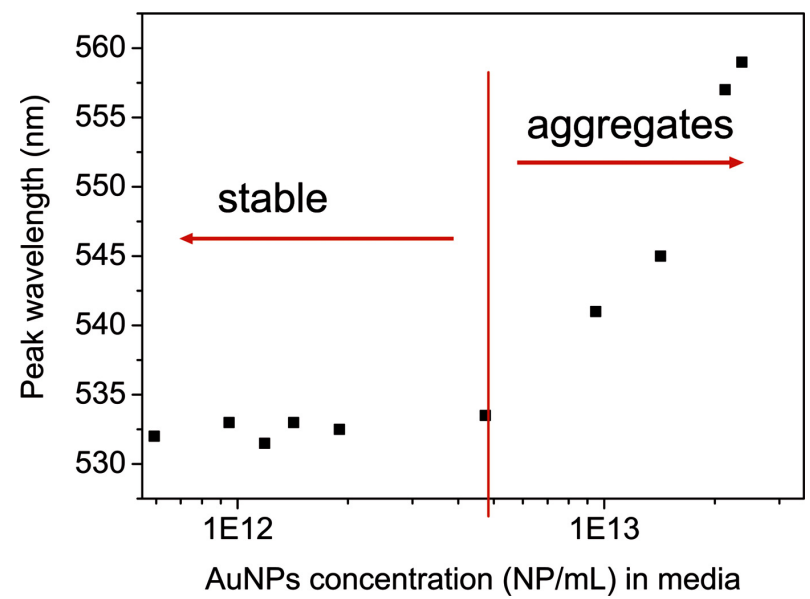

Figure 3. Stability in cell culture media (DMEM $+10 \%$ FBS) of increasing concentrations of MUA capped AuNPs. AuNPs are not stable at concentrations above $4.75 \times 10^{12} \mathrm{NP} / \mathrm{mL}$ of cell culture media. This is easily observed by the broadening and the large red-shift of the SPR band. On the other hand, stability is maintained at low concentrations due to the formation of the protein corona. 
media is not a limiting factor, the aggregation is likely due to a kinetic issue: The compression of the Stern layer induced by the high ionic strength of the media facilitates that the highly concentrated NPs contact between them before proteins would have the chance to be adsorbed onto the NP surface and confer steric stability.

It should be pointed out here that the dilutions of the NPs to achieve the desired concentration were prepared first and then $10 \%(\mathrm{v} / \mathrm{v})$ of this solution was added to the media. This methodology was followed along the present work since previous experiments showed that if a low volume - even a small drop - of a very high concentration of NPs is added to a large volume of CCM, AuNPs aggregate rapidly, even when the resultant mixture has a low NP concentration.

\section{Influence of the mixed layer composition and conformation on the stability of the conjugates}

All the AuNPs used in the following experiments were conjugated using a high concentration $(100 \mu \mathrm{M})$ of thiols $(\mathrm{MUA}+\mathrm{SH}-\mathrm{PEG}=100 \mu \mathrm{M})$, to ensure the excess of both components in every point so the conjugation equilibrium is rapidly reached. Comparison of conjugations using 10, 30 and $100 \mu \mathrm{M}$ of thiols can be found in the Supplementary Information. After washing the excess of ligand, $20 \mu \mathrm{L}$ of AuNPs $\left(2.4 \times 10^{14} \mathrm{NP} / \mathrm{mL}\right)$ were added to $180 \mu \mathrm{L}$ of $10 \%$ FBS-supplemented DMEM in all cases. The stability was assayed by measuring the SPR band by UV-VIS spectroscopy after 30 minutes (Figure 4a). As expected, AuNPs which had MUA predominance over SH-PEG aggregated in physiologic conditions. On the contrary, AuNPs became stable from ratios SH-PEG / MUA higher than 0.7 which coincides with the point where the rise in the hydrodynamic diameter, associated to a conformational change of the SH-PEG, was observed.

The stability at acidic pH was also tested. MUA-capped AuNPs are electrostatically stabilized due to the negative charge given by the deprotonated carboxylic groups. Therefore, MUAcapped AuNPs become unstable once the $\mathrm{pH}$ is decreased below its $\mathrm{pKa}$, and the carboxylic groups subsequently protonated (an effective surface charge of $>|30| \mathrm{mV}$ is needed to keep NPs stable in solution following the DVLO theory [44]). On the other hand, the sterically stabilized NPs should be stable at any $\mathrm{pH}$. To prove the stability of bifunctionalized AuNPs in the whole range of $\mathrm{pH}$, the $\mathrm{pH}$ of the AuNPs solution was brought to 2.6 by a Glycine / $\mathrm{HCl}$ buffer and the SPR band subsequently measured by UV-VIS spectroscopy (Figure 4b). Similarly as it was observed in the stability assay at physiologic conditions, the aggregation of NPs was evident for ratios of added SH-PEG / MUA lower than 0.7. Thus, here again the change in the mechanism of stabilization from electrostatic to steric coincides with the change in the conformation of SH-PEG.
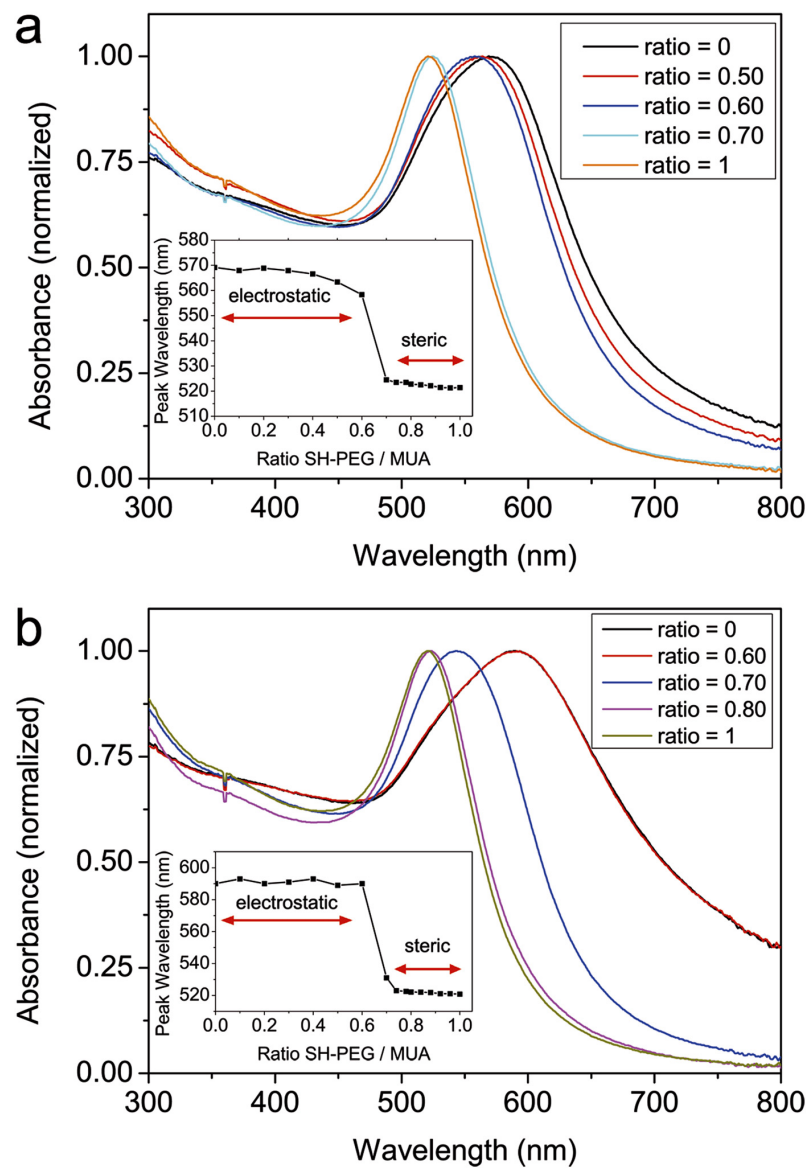

Figure 4. Stability in physiologic and acidic media of concentrated AuNPs. (a) The stability of AuNPs functionalized with different SH-PEG / MUA ratios was assayed by adding $10 \%$ of $2.4 \times 10^{14} \mathrm{NP} / \mathrm{mL}$ solution in DMEM supplemented with FBS. Destabilization caused a broadening and redshift of the SPR band. Stability is recovered due to the steric stabilization given by $\mathrm{SH}$ PEG in the brush conformation at ratios higher than 0.7 (b) To assay the stability in acidic media, the $\mathrm{pH}$ was decreased to 2.6. The protonation of the carboxylic groups causes the loss of colloidal stability when the stability of the NPs is governed by MUA. On the other hand, AuNPs remain stable when they are sterically stabilized (PEG in the brush conformation).

\section{Mixed monolayer interaction with protein corona}

The interaction between proteins present in the serum and NPs in physiological conditions has been widely explored [19, 22] and represents the most used methodology of stabilizing NPs (often unnoticed) in biological environments. In order to study the adsorption of proteins onto the different conjugates, our system was purified from the excess SH-PEG and MUA and then incubated with $10 \mu \mathrm{M}$ BSA overnight. Albumin was chosen as a model protein because it has been identified as the main serum protein absorbed to these type of NPs (negatively charged, $<50 \mathrm{~nm}$ NPs) [19]. The adsorption of protein was analyzed by DLS, UV-VIS and gel electrophoresis. 
It was observed an increase in the hydrodynamic diameter of AuNPs totally covered by MUA after adding BSA (Figure 5a). The size increase was $8.1 \mathrm{~nm}$ and it is explained by the adsorption of a monolayer of BSA on the MUA layer [45]. This size increase became only 5.2 and $3.7 \mathrm{~nm}$ at ratios 0.70 and 0.74 , respectively. The lower increase in size is attributed to less protein adsorption [46]. On the other hand, the hydrodynamic diameter was the same before and after addition of BSA for ratios higher than 0.78 , indicating that under these conditions the protein adsorption was completely inhibited.

The same tendency was observed in the SPR peak analysis (Figure 5b). The increase in the peak wavelength is attributed to the change in the surrounding dielectric environment of the $\mathrm{Au}$ surface due to the adsorption of protein [47]. This wavelength shift was up to $4.55 \mathrm{~nm}$ for MUA-capped AuNPs incubated with BSA. Also here the difference became smaller for ratios $>0.70(3.75 \mathrm{~nm})$. This difference decreased to 2.83, 2.17 , and $1.34 \mathrm{~nm}$ at ratios $0.74,0.78$, and 0.8 , respectively.

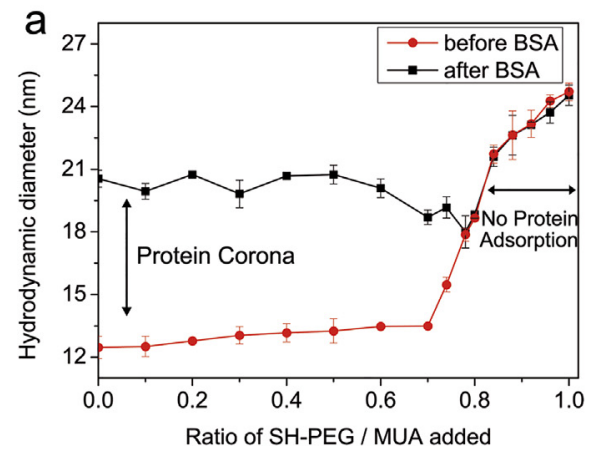

The difference was not significant at higher ratios. Thus, once again the point where PEG adopts the stretched conformation is related to a change on the physicochemical properties of the conjugate. In this case, it is clearly seen how the adsorption of protein can be nicely tuned in function of the composition of the mixed layer.

A very similar behavior was observed when full sera (FBS) was used instead of albumin (Figure S4). Protein corona was formed at ratios $<0.7$ as indicated by the increase of the hydrodynamic diameter and the shift of the SPR. Again, the adsorption was progressively reduced until ratios $>0.84$, when it was totally inhibited. Slight differences, such as a 5 $\mathrm{nm}$ larger hydrodynamic increase can be attributed to the complexity of the full sera respect to the one component (albumin) system.

Gel electrophoresis was performed to further confirm the different interaction with proteins when changing the composition of the monolayer (Figure 6). Relevant ratios of SH-

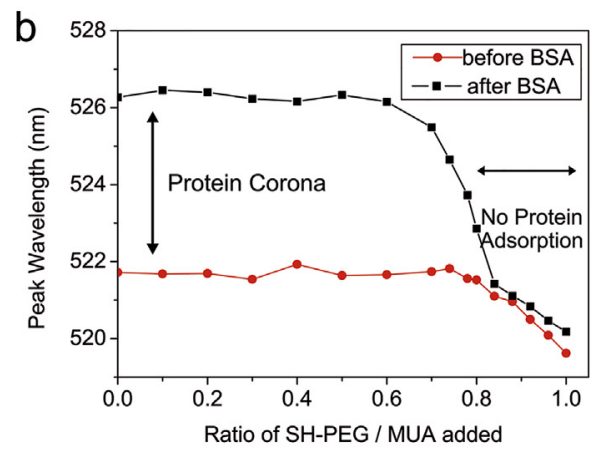

Figure 5. Tuning the protein adsorption. (a) Hydrodynamic Diameter before and after incubation with BSA. The formation of a protein corona at lower ratios is clearly related to the increase of the hydrodynamic diameter. The increase of size is minimized from ratio 0.70 . From ratios 0.78 to 1 this difference on size is negligible and therefore protein adsorption is totally inhibited. (b) SPR peak before and after incubation with albumin. The same behavior was found by analyzing the peak of the SPR band. The differences between before and after addition of albumin are reduced from ratios 0.7 to 0.8 . From 0.84 to 1 the differences are negligible.

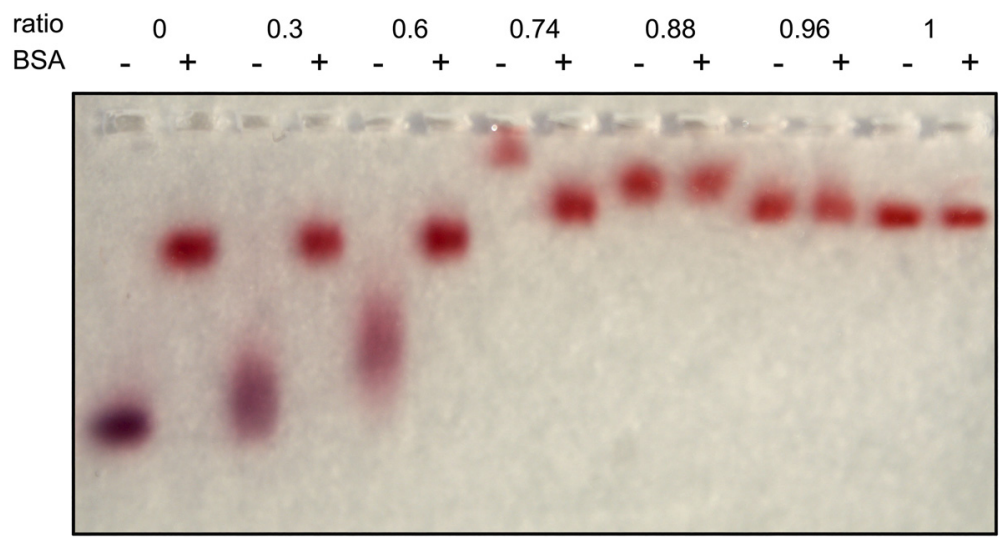

Figure 6. Agarose gel electrophoresis of relevant ratios with (+) and without $(-)$ albumin preincubation. The difference between the same AuNPs before and after the addition of albumin indicates the formation of a protein corona. This is inhibited at ratios $=0.88,0.96$ and 1 . The purplish color of the ratio $=0$ and 0.3 appeared only after drying the gel. 
PEG / MUA - AuNPs previously incubated overnight with and without albumin were loaded into the wells of a $1 \%$ agarose gel. The electrophoresis was run $1 \mathrm{~h}$ at $60 \mathrm{~V}$ in a $30 \mathrm{mM}$ sodium borate buffer at $\mathrm{pH}$ 8.5. A decrease of the electrophoretic mobility was observed for ratios $<0.74$, mainly due to an increase of the size after albumin adsorption, but also to a decrease of the surface charge. Note also that the electrophoretic mobility of AuNPs after albumin coverage is the same independently on their mobility without protein incubation. On the other hand, at ratios $>0.8$, the mobility is the same after incubation with albumin than without previous incubation, indicating that no modification of the size and/or surface charge was induced by albumin incubation. An intermediate behavior was observed for ratio $=0.74$. There is a difference between both conditions, but it is minimal. This latter case can be explained because the adsorption of albumin is not fully inhibited, but minimized.

Two different regimes can be distinguished from these results: (1) At added ratios SH-PEG /MUA from 0 to 0.7 , the SH-PEG has a low influence on the hydrodynamic diameter, since it is in the mushroom conformation. Here, the physicochemical properties are governed by MUA. Therefore, these AuNPs are not stable in physiologic media when working at concentrations higher than $5 \times 10^{12} \mathrm{NP} / \mathrm{mL}$, aggregate at acidic $\mathrm{pH}$ due to the protonation of carboxylic groups of MUA. In addition, these nanoconjugates showed the inability of PEG to confer steric stabilization in the mushroom conformation. (2) At added ratios from 0.7 to 1 , the SH-PEG changes the conformation from mushroom to brush and new physicochemical properties were subsequently acquired. These AuNPs are stable in physiological media at concentrations as high as $2.4 \times 10^{13} \mathrm{NP} / \mathrm{mL}$. Moreover, they are stable at the whole range of pHs because of the change in mechanism of stabilization from electrostatic to steric. The adsorption of protein is minimized or even inhibited depending on the amount of SH-PEG.

This has strong consequences on the design of NPs for medicine. For example, a different degree and type of complement activation, which ultimately depends on the recognition of the conjugates by specific proteins, was directly correlated with the conformation of the PEO monolayer on polymeric NPs in a recent work [11]. Briefly, Hamad et al showed that the complement activation was dramatically reduced for the nanospheres which have PEO chains in the brush conformation. The changes in the physicochemical properties of the NPs induced by the change of the PEG conformation, especially the different protein adsorption, can explain this different observed biological behavior.

\section{CONCLUSIONS}

The need of working with highly concentrated stable NPs in biomedical applications makes essential the search of methodologies to stabilize NPs in physiological conditions and monitor their physicochemical properties. The widely exploited spontaneous formation of protein corona may fail to stabilize NPs at high concentrations in physiological media. To overcome this problem, PEG has been proposed as an alternative to confer additional stability avoiding protein adsorption. However, this entails a decrease of functionality that can be overcome by mixed layers. Since these systems are more complex, a thorough characterization and understanding of the system is required. It is shown how changes in the stability in physiological media, stabilization mechanism, and protein adsorption are governed by the SH-PEG conformation on the mixed layer rather than by the composition. This is a key point in the stabilization by SH-PEG of AuNPs and it can be easily measured by common techniques such as DLS or UVVIS spectroscopy. The possibility of tuning the adsorption of proteins is also described here. This might have consequences in determining the final fate of NPs in organisms since important processes such as cell uptake [48] or activation of the complement systems are known to be influenced by the adsorption of proteins [11]. Last but not least, a properly designed mixed layer gives the opportunity to tune both functionality and stability of the NPs.

\section{MATERIALS AND METHODS}

All materials were used as received. $\mathrm{HAuCl}_{4}, 11$-MUA, sodium citrate, bovine serum albumin, sodium cyanide, CAPS, and DMEM (with $4500 \mathrm{mg}$ glucose/L, sodium bicarbonate and pyridoxine hydrochloride without L-Glutamine and phenol red) were obtained from Sigma-Aldrich. SH-PEG-CM (3.4 KDa) and SH-PEG-FITC (3.4 KDa) were obtained from Nanocs. All solutions described here were prepared in Milli-Q water.

\section{AuNPs synthesis}

AuNPs (14.6 $\mathrm{nm})$ were synthesized as reported in the literature. Roughly, Au seeds ( $9 \mathrm{~nm}, 4.2 \times 10^{12} \mathrm{NP} \mathrm{mL}{ }^{-1}$ ) were synthesized by adding an aqueous solution of $\mathrm{HAuCl}_{4}$ $(1 \mathrm{~mL}, 25 \mathrm{mM})$ to a boiling sodium citrate solution $(150 \mathrm{~mL}$, $2.2 \mathrm{mM}$ ). When the reaction was completed, the temperature was decreased to $90^{\circ} \mathrm{C}$ and $\mathrm{HAuCl}_{4}(1 \mathrm{~mL}, 25 \mathrm{mM})$ was added to the previously synthesized AuNPs. This step is repeated two more times in order to get the final AuNPs (14.6 nm, $4.2 \times 10^{12} \mathrm{NP} \mathrm{mL}^{-1}$ ).

\section{Functionalization of AuNPs}

The different SH-PEG / MUA ratios were prepared by mixing the corresponding volumes of $1 \mathrm{mM}$ (or $0.3 \mathrm{mM}$, or $0.1 \mathrm{mM}$ ) solution of each component. About $500 \mu \mathrm{L}$ of these mixtures were subsequently added to $4 \mathrm{~mL}$ of AuNPs as synthesized and softly mixed overnight. The SPR bands of the resulting conjugates were analyzed by UV-VIS spectroscopy at the range of 300-800 $\mathrm{nm}$. The hydrodynamic diameter was analyzed by DLS, the measures were repeated 
three times and the values represented here are the mean size expressed in number.

\section{Quantification of the SH-PEG-FITC loaded on the AuNPs by fluorescence}

The excess of SH-PEG-FITC and MUA was removed by three centrifugation steps (30000 rcf, $30 \mathrm{~min}$ ). After the last washing step, AuNPs were suspended in the same volume of an aquose $\mathrm{NaCN}$ solution (100 mM) and stirred for $6 \mathrm{~h}$ at $37^{\circ} \mathrm{C}$. The total dissolution of AuNPs was proved by the disappearance of the SPR. All the samples were buffered using CAPS (25 mM, pH 10.6). Known concentrations of SH-PEG-FITC under the same conditions were used to do the calibration curve. About $100 \mu \mathrm{L}$ of standards and samples were loaded in a 96-well plate and the fluorescence spectra $\left(\lambda_{\text {ex }}=494\right.$, $\lambda_{\text {em }}=521$ ) was taken. The concentration of SH-PEG-FITC in the samples was calculated from the calibration curve.

\section{Quantification of the SH-PEG-FITC by absorbance}

AuNPs were removed from the sample by three centrifugation steps $(30,000 \mathrm{~g}, 30 \mathrm{~min})$. About $25 \mu \mathrm{L}$ of CAPS buffer (200 $\mathrm{mM}, \mathrm{pH}$ 10.6) were added to $975 \mu \mathrm{L}$ of the resulting supernatant. To prepare the standards the same procedure than the explained above to functionalize the AuNPs was followed but using sodium citrate $2.2 \mathrm{mM}$ instead of the AuNPs solution. The absorbance of standards and samples were measured under the same conditions. The amount of SHPEG-FITC loaded on the AuNPs was calculated subtracting the concentration of the sample from the concentration of the standard.

\section{Stability in physiological and acidic media}

AuNPs functionalized with MUA and SH-PEG were concentrated to $2.4 \times 10^{14} \mathrm{NP} / \mathrm{mL}$ by centrifugation (18000 rcf, $14 \mathrm{~min}$.) of $1 \mathrm{~mL}$ of AuNPs and resuspension of the pellet in a final volume of $20 \mu \mathrm{L}$. Then these $20 \mu \mathrm{l}$ were added to $180 \mu \mathrm{L}$ of DMEM supplemented with $10 \%$ FBS and softly mixed during 30 minutes. To assay the stability in acidic media, $1 \mathrm{~mL}$ of previously functionalized AuNPs were brought to $\mathrm{pH} 2.6$ by adding $2.5 \mu \mathrm{L}$ of a $0.2 \mathrm{M}$ glycine/ $\mathrm{HCl}$ buffer. The stability in both cases was evaluated by analyzing the broadening and the red-shift of the SPR band.

\section{Protein adsorption}

About $1.3 \mathrm{mM}$ solution of bovine serum albumin was prepared by diluting $182 \mathrm{mg}$ in $2.1 \mathrm{~mL}$ of $5 \mathrm{mM}$ Hepes buffer at $\mathrm{pH}$ 7.5. Then $7.7 \mu \mathrm{L}$ of this solution was added to $1 \mathrm{~mL}$ of previously functionalized AuNPs and softly mixed overnight. The changes of the hydrodynamic diameter were analyzed by DLS and the shift of the SPR band by UV-VIS. In the case of experiments with full serum, $10 \mu \mathrm{L}$ of deactivated FBS were added to $1 \mathrm{~mL}$ of AuNPs solutions.

\section{Gel electrophoresis}

AuNPs were functionalized with relevant ratios of SH-PEG / MUA (0, 0.3, 0.6, 0.74, 0.88, 0.96, and 1) as explained above. Then the samples were split in two parts. $1 \mathrm{~mL}$ was incubated with $7.7 \mu \mathrm{L}$ of a $1.3 \mathrm{mM}$ BSA solution in $5 \mathrm{mM}$ Hepes buffer $(\mathrm{pH} 7.5) \mathrm{o} / \mathrm{n}$ and the other part was kept without any modification. Samples were loaded into the wells of a $1 \%$ agarose gel. The electrophoresis was run under $60 \mathrm{~V}$ in a sodium borate buffer ( $30 \mathrm{mM}, \mathrm{pH} 8.5)$.

\section{SUPPLEMENTARY MATERIAL}

Calibration curves, loading of thiols at different concentrations, evolution of the hydrodynamic diameter using different concentration of thiols, and study of the protein corona formation using full serum can be found in the supplementary material.

\section{REFERENCES}

[1] Ghosh P, Han G, De, M, Kim CK, Rotello VM. Gold nanoparticles in delivery applications. Adv Drug Deliv Rev. 2008; 60(11):130715. doi:10.1016/j.addr.2008.03.016

[2] Pissuwan D, Niidome T, Cortie MB. The forthcoming applications of gold nanoparticles in drug and gene delivery systems. J Control Release. 2011;149(1): 65-71. doi:10.1016/j.jconrel. 2009.12.006

[3] Taylor A, Wilson KM, Murray P, Fernig DG, Lévy R. Long-term tracking of cells using inorganic nanoparticles as contrast agents: are we there yet? Chem Soc Rev. 2012;41(7):2707. doi:10.1039/c2cs35031a

[4] McMahon SJ, Hyland WB, Muir MF, Coulter JA, Jain S, Butterworth KT, Schettino G, Dickson GR, Hounsell AR, O'Sullivan JM, Prise KM, Hirst DG, Currell FJ. Biological consequences of nanoscale energy deposition near irradiated heavy atom nanoparticles. Sci Rep. 2011;1:18. doi:10.1038/srep00018

[5] Singh KP, Gupta S. Nano-QSAR modeling for predicting biological activity of diverse nanomaterials. RSC Adv. 2014;4(26):1321530. doi:10.1039/c4ra01274g

[6] Walkey CD, Olsen JB, Guo H, Emili A, Chan WCW. Nanoparticle size and surface chemistry determine serum protein adsorption and macrophage uptake. J Am Chem Soc. 2012;134(4):2139-47. doi:10.1021/ja2084338

[7] Smith PJ, Giroud M, Wiggins HL, Gower F, Thorley JA, Stolpe B, Mazzolini J, Dyson RJ, Rappoport JZ. Cellular entry of nanoparticles via serum sensitive clathrin-mediated endocytosis, and plasma membrane permeabilization. Int J Nanomedicine. 2012;7: 2045-55.

[8] Avgoustakis K, Beletsi A, Panagi Z, Klepetsanis P, Karydas AG. PLGA - mPEG nanoparticles of cisplatin : in vitro nanoparticle degradation, in vitro drug release and in vivo drug residence in blood properties. 2002;79:123-135.

[9] Lipka J, Semmler-Behnke M, Sperling RA, Wenk A, Takenaka S, Schleh C, Kissel T, Parak WJ, Kreyling WG. Biodistribution of PEG-modified gold nanoparticles following intratracheal instillation and intravenous injection. Biomaterials. 2010;31(25):657481. doi:10.1016/j.biomaterials.2010.05.009

[10] Xiaohu X, Yang M, Wang Y, Zheng Y, Li Q, Chen J, Xia Y. Quantifying the coverage density of poly(ethylene glycol) chains on the surface of gold nanostructures. ACS Nano. 2012;6(1):512-22. 
[11] Hamad I, Al-Hanbali O, Hunter AC, Rutt KJ, Andresen TL, Moghimi SM. Distinct polymer architecture mediates switching of complement activation pathways at the nanosphere-serum interface: implications for stealth nanoparticle engineering. ACS Nano. 2010;4(11):6629-38. doi:10.1021/nn101990a

[12] Ojea-Jiménez I, Puntes V. Instability of cationic gold nanoparticle bioconjugates: the role of citrate ions. J Am Chem Soc. 2009;131: 13320-27.

[13] Free P, Shaw CP, Lévy R. PEGylation modulates the interfacial kinetics of proteases on peptide-capped gold nanoparticles. Chem Commun. 2009;33:5009-11. doi:10.1039/b910657j

[14] Lim IS, Goroleski F, Mott D, Kariuki N, Ip W, Luo J, Zhong C.-J. Adsorption of cyanine dyes on gold nanoparticles and formation of J-aggregates in the nanoparticle assembly. $J$ Phys Chem $B$. 2006;110(13), 6673-82. doi:10.1021/jp057584h

[15] Ruenraroengsak P, Cook JM, Florence AT. Nanosystem drug targeting: facing up to complex realities. J Control Release. 2010;141(3):265-76. doi:10.1016/j.jconrel.2009.10.032

[16] Vasir JK, Reddy MK, Labhasetwar VD. Nanosystems in drug targeting: opportunities and challenges. 2005;18:47-64.

[17] Murdock RC, Braydich-Stolle L, Schrand AM, Schlager JJ, Hussain SM. Characterization of nanomaterial dispersion in solution prior to in vitro exposure using dynamic light scattering technique. Toxicol Sci. 2008;101(2):239-53. doi:10.1093/toxsci/kfm240

[18] Mahl D, Greulich C, Meyer-Zaika W, Köller M, Epple M. Gold nanoparticles: dispersibility in biological media and cell-biological effect. J Mater Chem. 2010;20(29):6176. doi:10.1039/c0jm01071e

[19] Casals E, Pfaller T, Duschl A, Oostingh GJ, Puntes V. Time evolution of the nanoparticle protein corona. 2010;4(7):3623-32.

[20] Kim B, Han G, Toley BJ, Kim C-K, Rotello VM, Forbes NS. Tuning payload delivery in tumour cylindroids using gold nanoparticles. Nat Nanotechnol. 2010;5(6):465-72. doi:10.1038/nnano.2010.58

[21] Perrault SD, Walkey C, Jennings T, Fischer HC, Chan WCW. Mediating tumor targeting efficiency of nanoparticles through design. Nano Lett. 2009;9(5):1909-15. doi:10.1021/nl900031y

[22] Cedervall T, Lynch I, Lindman S, Berggard T, Thulin E, Nilsson H, Dawson KA, Linse S. Understanding the nanoparticle-protein corona using methods to quantify exchange rates and affinities of proteins for nanoparticles. Proc Natl Acad Sci USA. 2007; 104(7):2050-55. doi:10.1073/pnas.0608582104

[23] Nowinski AK, White AD, Keefe AJ, Jiang S. Biologically Inspired Stealth Peptide-Capped Gold Nanoparticles. Langmuir. 2014;30 (7):1864-70. doi:10.1021/la404980g

[24] Love JC, Estroff LA, Kriebel JK, Nuzzo RG, Whitesides GM. Selfassembled monolayers of thiolates on metals as a form of nanotechnology. 2005;105:1103-69.

[25] Comenge J, Sotelo C, Romero F, Gallego O, Barnadas A, Parada TG, Domínguez F, Puntes VF, Rozhkova EA. Detoxifying antitumoral drugs via nanoconjugation: the case of gold nanoparticles and cisplatin. PLoS One. 2012;7(10):e47562. doi:10.1371/ journal.pone.0047562.s005

[26] Du D, Ding J, Cai J, Zhang J, Liu L. In situ electrodeposited nanoparticles for facilitating electron transfer across selfassembled monolayers in biosensor design. Talanta. 2008;74(5): 1337-43. doi:10.1016/j.talanta.2007.09.003

[27] Bastus NG, Comenge J, Puntes V. Kinetically controlled seeded growth synthesis of citrate-stabilized gold nanoparticles of up to 200 Nm: size focusing versus Ostwald Ripening. 2011, 11098-11105.

[28] Sperling R, Casals E, Comenge J, Bastus N, Puntes V. Inorganic engineered nanoparticles and their impact on the immune response. Curr Drug Metab. 2009;10:895-904.

[29] Mei BC, Susumu K, Medintz IL, Mattoussi H. Polyethylene glycolbased bidentate ligands to enhance quantum dot and gold nanoparticle stability in biological media. Nat Protoc. 2009; 4(3):412-23. doi:10.1038/nprot.2008.243
[30] Farokhzad OC, Cheng J, Teply BA, Sherifi I, Jon S, Kantoff PW, Richie JP, Langer R. Targeted nanoparticle-aptamer bioconjugates for cancer chemotherapy in vivo. Proc Natl Acad Sci USA. 2006;103 (16):6315-20. doi:10.1073/pnas.0601755103

[31] Owens D, Peppas, N. Opsonization, biodistribution, and pharmacokinetics of polymeric nanoparticles. Int J Pharm. 2006;307 (1):93-102. doi:10.1016/j.ijpharm.2005.10.010

[32] Suh J, Choy KL, Lai SK, Suk JS, Tang BC, Prabhu S, Hanes J. PEGylation of nanoparticles improves their cytoplasmic transport. Int J Nanomedicine. 2007;2:735-41.

[33] Mei BC, Oh E, Susumu K, Farrell D, Mountziaris TJ, Mattoussi H. Effects of ligand coordination number and surface curvature on the stability of gold nanoparticles in aqueous solutions. Langmuir. 2009;25:10604-11.

[34] Sellers H, Shnidman Y, Eilerss JE, Langmuir RM. Structure and binding of alkanethiolates on gold and silver surfaces: implications for self-assembled monolayers. J Am Chem Soc. 1993;111 (21):9389-401.

[35] Wang Y, Zeiri O, Neyman A, Stellacci F, Weinstock AI. Nucleation and island growth of alkanethiolate ligand domains on gold nanoparticles. ACS Nano. 2012;6(1):629-40.

[36] Simpson CA, Agrawal AC, Balinski A, Harkness KM, Cliffel DE. Short-Short-chain PEG mixed monolayer protected gold clusters increase clearance and red blood cell counts. ACS Nano. 2011;5 (5):3577-84.

[37] Tagliazucchi M, Blaber MG, Schatz GC, Weiss EA; Szleifer I. Optical properties of responsive hybrid Au@polymer nanoparticles. ACS Nano. 2012;6:8397-406.

[38] Tsai D.-H, DelRio FW, MacCuspie RI, Cho T], Zachariah MR, Hackley VA. Competitive adsorption of thiolated polyethylene glycol and mercaptopropionic acid on gold nanoparticles measured by physical characterization methods. Langmuir. 2010;26:10325-33.

[39] Louguet S, Kumar AC, Guidolin N, Sigaud G, Duguet E, Schatz C. Control of the PEO chain conformation on nanoparticles by adsorption of PEO-block-poly (L-Lysine) copolymers and its significance on colloidal stability and protein repellency. 2011;27(21):12891-901.

[40] Ipe BI, Shukla A, Lu H, Zou B, Rehage H, Niemeyer CM. Dynamic light-scattering analysis of the electrostatic interaction of hexahistidine-tagged cytochrome P450 enzyme with semiconductor quantum dots. Chemphyschem. 2006;7:1112-18.

[41] Kimling J, Maier M, Okenve B, Kotaidis V, Ballot H, Plech A Turkevich method for gold nanoparticle synthesis revisited. 2006;110(32):15700-707.

[42] Saha K, Agasti SS, Kim C, Li X, Rotello VM. Gold nanoparticles in chemical and biological sensing. Chem Rev. 2012;112:2739-79.

[43] Lynch I, Salvati A, Dawson KA. Protein-nanoparticle interactions: what does the cell see? Nat Nanotechnol. 2009;4:546-47.

[44] Sonavane G, Tomoda K, Makino K. Biodistribution of colloidal gold nanoparticles after intravenous administration: effect of particle size. Colloids Surf B Biointerfaces. 2008;66;274-80.

[45] Bastús NG, Casals E, Vázquez-Campos S, Puntes V. Reactivity of engineered inorganic nanoparticles and carbon nanostructures in biological media. Nanotoxicology. 2008;2;99-112.

[46] Ardao I, Comenge J, Benaiges MD, Álvaro G, Puntes VF. Rational nanoconjugation improves biocatalytic performance of enzymes: aldol addition catalyzed by immobilized rhamnulose-1-phosphate aldolase. Langmuir. 2012;28;6461-67.

[47] Eck D, Helm CA, Mainz D. Plasmon resonance measurements of the adsorption and adsorption kinetics of a biopolymer onto gold. 2001;17:1999-2002.

[48] Chithrani, BD, Chan, WCW. Elucidating the mechanism of cellular uptake and removal of protein-coated gold nanoparticles of different sizes and shapes. Nano Lett. 2007;7: 1542-50. 


\section{COMPETING INTERESTS}

The authors declare no competing interests.

\section{PUBLISHING NOTES}

(C) 2015 J. Comenge and V. F. Puntes. This work has been published open access under Creative Commons Attribution License CC BY 4.0, which permits unrestricted use, distribution, and reproduction in any medium, provided the original work is properly cited. Conditions, terms of use and publishing policy can be found at www.scienceopen.com.
Please note that this article may not have been peer reviewed yet and is under continuous post-publication peer review. For the current reviewing status please click here or scan the QR code on the right.

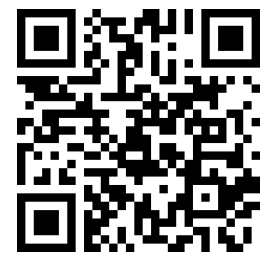

\section{ScienceOPEN.com}

